\title{
Issues of Cyber Laws and IPR in Software Industry and Software Process Model
}

\author{
Arun Kumar B. R \\ Asst.Professor \& HOD, MCA Dept. \\ Sir M Visvesvaraya Institute of Technology \\ Bangalore, Karnataka, India.
}

\begin{abstract}
In conventional requirement engineering functional requirements are much focused. If non-functional requirements including cyber space issues are not specified in advance, software will be a matter of cyber accident affecting the society and economy. The greatest threat of risk to software industry, engineering process and education is due to lack of future imagination and inability to understand strongest bond established between software engineering discipline and legal issues of the cyber space.

It is very high time to address the legal issues in software industry, software process model (SPM) and software education. This research focuses it's work on critical legal issues namely Intellectual Property Rights (IPR) and cyber law (CL) as key quality determining factors in the software process model and hence in Industry.
\end{abstract}

\section{General Terms}

Cyber Laws and IPR in Software Industry and Software Process Model

\section{Keywords:}

Intellectual Property Rights, Cyber Laws, functional, nonfunctional requirements engineering, software process model.

\section{INTRODUCTION}

The advent of computers/electronic devices as a basic tool of communication, digital data, digital content, information processing, information storage, physical devices control, multimedia software applications on the internet, applications that run across different countries of the globe, etc., has lead to visualize a new cyber world and hence cyber society. This cyber society functions on a virtual world created by technology [5][8][16][17][18] in an overlapping relation with almost all the discipline of engineering including software engineering.

As defined under Section 2(i) of Indian Information Technology Act 2000, a computer is a electronic machine that accepts data and instructions as input, allows it to be stored and manipulated; and processes (computes) the data at high speed and gives information / data as output (result) (www.computerhope.com/ jargon/ c/ computer.htm).

At present, legal system and framework are inadequate to address all the aspects of Information Technology (IT) [7]. As and when new computing technologies walks into the life style, law has to learn the changes. A lot of grey areas exist in the legal system are billion dollar questions to the software industry and should evolve on a continuous process. All the countries are working hard on these grey areas to address various problems. Presently, the law (Statutory or otherwise) providing answers to these problems or dealing with the Information
Technology is termed as 'Computer Laws' or 'Information Technology Laws' or 'Cyber laws'. In a cyber space, there are significant areas to be investigated such as E-commerce, Protection of Intellectual Property, issues relating to morality qua Freedom of Expression, and law relating to Privacy, Cyber jurisdiction and Cyber crimes [7].

In general, Intellectual Property Right Laws (IPR) includes copyright, rules on fair use, special rules on copy protection for digital media, etc. The software patents is an area of controversy and in infancy in several countries [21].

Cyber law or Internet law (CL) is a term that internally represents the legal issues related to use of the Internet. CL is readily distinguishable from IPR. CL is not completely evolved as a subject of investigation in the context of software development, use and etc. One can understand that IPR has its application in the domain of CL.

Virtual worlds are important integral parts of today's life style Every neitizen is more used to connect to the virtual worlds through the computers and other communicating devices. In a Cyber space, the virtual worlds have to use devices (softwares) that obey the $\mathrm{CL}$ and cyber ethics. Therefore, software development for such devices needs to be in a legal environment. Hence, CL and IPR are essentially key issues in software industry and as well as in software development process.

\subsection{Related Work}

A lot of research work has been done related to software engineering, software process models and quality software. From the perspective of the existing literature, most of the work addresses the functional requirements and a few on nonfunctional requirements ( NFR). The use of NFR during the software development process is incomplete without legal issues similar to IPR and CL [10] [11] [12] [16] [17] [18]. Several research papers have appreciated Chung's NFR Framework that uses non-functional requirements to drive design and to support architectural design [13]14]. In an extensive literature survey carried out, this work did not have come across several software process models (except the work of Paul Klint) or NFR framework which tackles legal issues such as IPR, CL, etc including Chung's work. This research work discuses cyber law and IPR key issues in software industry and software process model.

This paper has been organized into different sections. Section 2 to presents awareness of IPR and CL in some countries. Section 3 discusses IPR and CL issues in IT industry. Section 4 lists the research questions designed for software industry. Section 5 brings out the role of IPR and CL in requirement analysis. IPR and CL based system development life cycle is offered in section 6. Section 7 concludes the work. 


\section{IPR/CL AWARENESS IN DIFFERENT COUNTRIES}

IPR is as an intangible asset, which serves as a competitive advantage to any nation. Legal awareness campaigns in almost all countries have started. Some of the countries news is given below:

Taiwan is ranked the third largest IT products manufacturing country world-wide with US $\$ 15$ billion production value in 1995. The promotion of IPR awareness and computer literacy has brought increased prosperity to the computer-related market [3].

Mr. Wang Jinzhen, Vice Chairman, China Council for the Promotion of International Trade, has said "Innovation is the core of the nation's competitiveness". China's innovation strategy has initiated campaign against IP infringement and steps up anti-piracy fight (http://www.usibc.com/sites/ default /files / initiatives /files/mr. wangjinzhen.pdf). Enforcement of any form of IPR in China can be undertaken by way of the administrative enforcement procedure or judicial procedure [19].

Mr. Pavan Duggal, Advocate Supreme Court of India, Cyber law consultant has said in his one of the articles that the new proposed Convergence Law in India aims to promote, facilitate and develop in an orderly manner the carriage and content of communications including broadcasting, telecommunications and multimedia. It further aims to establish an autonomous commission to regulate carriage of all forms of communication. The IT firm in India need to be aware of such laws and software process stake holders should be trained enough to ensure the same.

Both developing and developed countries have taken serious steps on the legal issues. We can find IPR infringement and cyber law violation cases lower in countries with stiffer penalties, for example in China. In India, the government has initiated various steps towards IPR protection and there is a turn down in the levels of piracy. Now, it is dire need to take up these issues in software Industry and process models.

\section{IPR AND CL ISSUES IN IT INDUSTRY}

Continuous, rapid changes and explosive growth in the pervasive computer technologies demands new focus with thorny legal questions and scrutiny in cyber society especially when information technology is used in negative way. Every component of the computer is an instance of the class Cyber world. Hence, all aspects of the laws of the cyber world are applicable to every component created. It is essential to realize that, Legal knowledge of Cyber law, and cyber ethics are the prerequisites for every stake holder irrespective of their positions and roles in IT industry.

The next equally important legal issue to be considered in software product and technology companies is IPR. To succeed in the world market companies from India today need brand building skills and protect their IPR (http://www.igovernment.in/site/indian-it-firms-are-nowfocusing-securing-ipr). The height of awareness growth in Indian IT industry in terms of IPR may be good but not in terms of CL. The IT fraternity should take great efforts in both terms.

The existing legal views of Copyright law and patent law are not completely matching with natural technical views of the software [6]. The IT industry needs to be worked out with law authorities to come out with an agreement on "the rules of fair following". This is the most basic requirement that need to be periodically done as rules are not clear and keep changing.

On the other side of the coin, knowledge of IPR and CL are critical and central issues which have posed hitherto unmatched challenges in all disciplines of engineering including software engineering, Telecommunication engineering, information security engineering, Biotechnology, etc. Today, information technology has cut across all the disciplines and subsists as an integral part [5].

Today, IT industry needs to be attentive to CL framework and on several grey areas which are imposing challenges related to the implementation, enforcement and jurisdiction of the Act.

In the present global circumstances, cyber law enforcement in the every step of software engineering process is a quality control mechanism. The system can not be stronger than the weakest link in the chain. To ensure quality software, legal issues have to be taken care in early stages of computing technologies development. At the same time, one has to note that territorially-based law-making and law-enforcing authorities have further increased the time, analysis and cost complexity of the software development.

The software development and its services require substantial investments of work, money and time. It is prime duty to legally protect investors in R\&D in terms of copyrights and patents Several research works have claimed that both software copyrights and patents have positive effects on the performance of IT firms [1].

The software and patenting may be controversial; the software and patent debate is the argument dealing with the extent to which it should be possible to patent software and computer-implemented inventions as a matter of public policy. At this juncture the concern is also to ensure whether the software development itself is legal (uses legal software for development, etc.,) and to analyze the outcomes for patenting during the course of software development.

In Indian context, the Intellectual property rights are dealt under the provision of Indian Copyright Act, 1957. The Act does not have any section dealing with piracy of computer software from the internet. Though the Act, when it comes to software takes care of offline piracy, it fails when it has to deal with online piracy.

The rapid development of Internet and Computer technology globally has led to the growth of new forms of worldwide crime especially on the Internet. These crimes have virtually no boundaries and may affect any country across the globe. Thus, there is a need for awareness and ratification of necessary legislation in all countries for the prevention of cyber crimes [8].

Even though software IPRs and cyber laws play an important role in software process and crucial for innovative activity for output growth in software firms, it is seemingly an undeniable fact that there have not been sufficient researches on IPR based software engineering process and cyber laws issues in phases of software engineering process and its implications in quality assurance of the software [2] [4]. 


\section{POINTS TO PONDER}

This work has designed and listed several research questions based on issues of IPR and CL to be discussed by the software industry. Some of the Points to ponder are [5] [6] [7]:

a) What is copyrighted on contents available on Internet?

b) How should one decide where the copyright infringement has taken place?

c) Who should be held liable for copyright infringement and how?

d) How the balance is to be achieved in protecting the works of the author and the usage and awareness of works of such authors?

e) How to ensure software developed has not violated law (IPRL and CL) of any country?

f) What technical measures are taken to ensure that software is not releasing any viruses?

g) Whether the multimedia application developed has not violated copyright (of music companies) of any country?

h) How to ensure website in one country (for example, India) has not infringed the patent rights of any other country?

i) How do you find the right owner of the right digital content?

j) Is software developed violates privacy rights of an individual?

The listing of such questions may not end. A lot of ambiguous legal issues exist. Such legal issues are risk factors in developing quality software if not addressed during requirements engineering.

\section{IPR AND CL ISSUES IN REQUIREMENT ANALYSIS}

As far as non-functional and domain requirements in software development process is concerned lack of knowledge of IPR and $\mathrm{CL}$ could drive into cyber catastrophe resulting in misbehaving software functionalities and a loss to the society in general and serious implications on Governance, Business, Crimes, Entertainment, Information delivery, Education etc.,

To ensure that Software development does not violate the Cyber Laws and enforces IPR calls for paradigm shift in analyzing and modeling non-functional and domain requirements in order to deliver quality and legal Software product.

A Software application which works on any aspects of the cyber society obviously bounded by cyber laws. The software developed may work on the internet which is borderless. In case of the internet, Issues of jurisdiction and sovereignty have promptly come to the forefront, since there is no uniform international jurisdictional law of universal application, and such questions are generally a matter of conflict of laws, etc. These issues make requirements engineering challenging, complex and costly. In addition to it every stakeholder need to be aware of the challenges ahead of them and how they are being addressed in every step of software engineering process. This makes the existing complex and crucial Non functional and domain analysis further complicated. In addition to it, the possible mappings between functional and nonfunctional requirements needs to be worked out.

It is very essential to ensure that implementation of every functional, non-functional and domain requirement of the software under development has not violated the IPR and CL. For example, a requirement should not have been implemented by using pirated software and should not function violating the cyber law \& IPR.

For example, Piracy occurs when copyrighted software is made available to users to download without the express permission of the copyright owner. Copy right piracy is a serious crime which hampers creativity, hinders the development of software industry and ultimately effects economy of e-commerce at national and international level.

In business context the quality of software engineering refers to two related but distinct notions [15]:

i) Software functional quality reflects how well it complies with or conforms to a given design, based on functional requirements (FR) or specifications [15] .

ii) In general, Software structural quality refers to how it meets non-functional requirements (NFR) that support the delivery of the functional requirements, such as robustness or maintainability, the degree to which the software was produced correctly.

Now, it is high time to consider legal issues in NFR and domain requirement analysis.

It is required to ensure that every requirement (FR or NFR) conforms to cyber law / IPR and meets the customer expected functionality. Every software development iteration may be validated and verified in consultation with some international board certified lawyer authorized to engage in multijurisdictional practices as well as acceptance has to be obtained by the customer.

As we are aware, software requirements specification (SRS) is a comprehensive description of the intended purpose and environment for software under development. The SRS should fully describe

i) What the software will do and how it will be expected to perform?

ii) What are the legal non-functional and domain requirements and how they are implemented?

We know that SRS is a documentation of good understanding of project analysis to minimize the time and effort required by developers to achieve desired goals, reduce development cost and facilitates testing.

SRS facilitates validation of the software to ensure all the requirements specified in the SRS such as the functionality features, performance, design, and quality of the software. It is also required to verify how design of each requirement is implemented and the behavior of each function executes to other feature of the software [9]

As SRS is the organization of the project, addressing the complete requirements and relevant keys of the software will avoid confusion and issues throughout the development, testing 
and delivery stage of the project. Therefore, SRS and Software Testing are relatively essential to achieve the overall functionality, quality attributes and performance of the project [9].

Therefore, it is highly essential to execute SRS analysis and ensure that it is properly understood by both parties in the view of customer functional requirements and legal requirements.

Legal non-functional requirements (quality factors) as applicable to the given problem need to be identified, a checklist may be documented and prioritizing them may be beneficial. This list needs to be evaluated, dependency relationship among nonfunctional and functional requirements have to be identified. The check list needed to be redefined and documented.

In the perspective of cyber space issues, non-functional requirements are the legal constraints under which a system operates. As application of the software changes characterization of NFR changes. There exists diversity in characterization of NFR and it is subjected to the application domain.

It is highly essential to formulate the non-functional requirements. The characterizing and formulating NFR in [20] is centered around quality attributes such as maintainability, modularity, etc but omits the legal issues. This work modifies the formulation to include these key legal issues such as IPR, $\mathrm{CL}$, etc and the same is shown in the table below (Table-1).

Legal issues of the cyber space have to be given attention while eliciting, analyzing, documenting and tracking functional, nonfunctional requirements and domain requirements. Otherwise, the development may have to be compromise with the quality of the product, the cost to develop and enhance it, and the time-tomarket of current and future releases. As mentioned in [9], without quality targets to guide the architects and engineers, design choice are random, and it is tough to assess the system during architecture and design reviews and system test.

\section{Table-1: Formulating NFR including Cyber space issues} (IPR, CL, etc).

Non-functional requirements
1. What is your definition of nonfunctional requirements?

2. Does it defines the cyber space legal issues such as IPR, $\mathrm{CL}$, etc., as part of NFR?

3. What are the general relationships between typical quality attributes and features?

4. What are the legal constraints that bind the specific functional requirement?

5. Verify, validate and obtain the formal approval of the legal constraints identified from a legal authority.

6. How can non-functional requirements (attributes) be allocated to development activities?

\begin{tabular}{|l|l|}
\hline Requirements traceability & $\begin{array}{l}\text { 1. What should be traced? } \\
\text { 2. How and when to trace it? }\end{array}$ \\
\hline Structuring the RE process & $\begin{array}{l}\text { 1. Is requirements formalization } \\
\text { software quality? } \\
\text { necessary to improve software } \\
\text { quality? }\end{array}$ \\
& $\begin{array}{l}\text { 2. What's the scope of the user? } \\
\text { 3. How to deal with requirements } \\
\text { overload? }\end{array}$ \\
\hline
\end{tabular}

\section{IPR \& CL BASED SYSTEM DEVELOPMENT LIFE CYCLE (IPRCL- SDLC)}

System Development Life Cycle (SDLC) is defined as the process (as a whole) of developing high quality system or software to meet assured requirements. Requirements Engineering, Design, Implementation, Testing and Maintenance are universally known phases of SDLC. In Each SDLC phase, a Validation and

Verification $(\mathrm{V} \& \mathrm{~V})$ sub-phase controls the quality of the deliverables. It is highly desired to carry out the verification and validation $(\mathrm{V} \& \mathrm{~V})$ with respect to functional, non-functional and domain requirements mapped to legal issues also. It is highly desirable and essential to analyze the possible internal relationship that may exist between the functional, nonfunctional and domain requirements. Generally, in non-legal based SDLC V\&V is confined to customer requirement functionalities. Though NFR and DR analysis/design is done, it lacks in terms of cyber space issues. This work devices IPR and CL issues based SDLC (IPRCL-SDLC). In literature survey even though patent based software life cycle is documented (Paul Klint 2006, //homepages.cwi.nl paulk/patents /isnot/node7.html), it does not address the question like whether the system/software being developed violates the CL. 


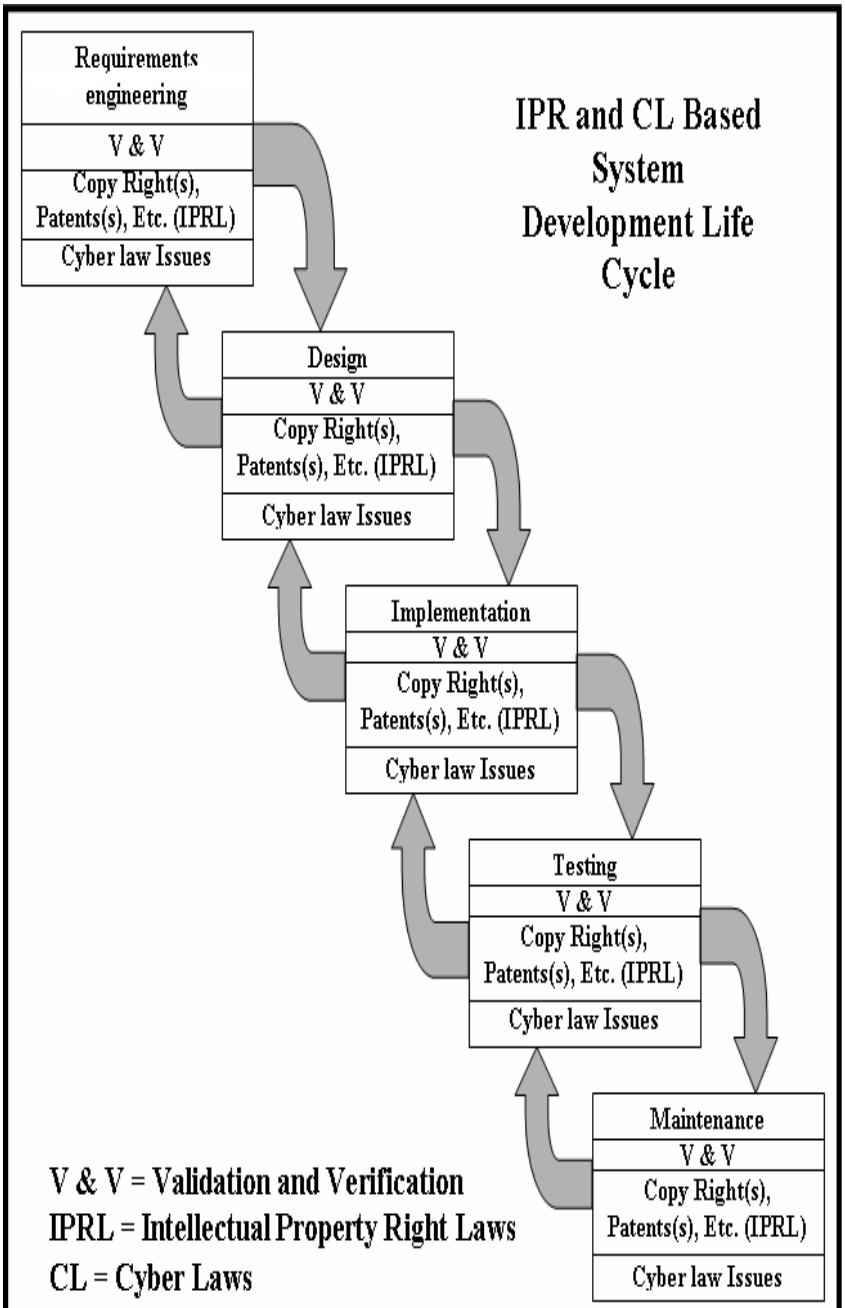

Fig 1. IPR and CL based system development life cycle.

This work has designed IPRCL-SDLC that takes into account IPR as well as CL during software development. In each V\&V sub-phase, in addition to questions on Copy rights, patents, etc (IPR), CL issues have to be addressed. The Fig 1, above shows IPR and CL based system development life cycle.

\section{CONCLUSION}

This work enlightens on the legal issues such as IPR and CL in software Industry and development. It List outs a sample set of research questions to be addressed by industry during the software development. A modified formulation of nonfunctional requirements including the legal issues is presented. IPR and CL based SDLC brings out the paradigm shift in legal issues analysis and incorporating the same into software development.

In summary, IPR and CL are critical issues in every stage of software development life cycle, right from requirements engineering and failing to incorporate them may lead to cyber accidents, crime, software piracy etc,. These legal issues are inevitable even though it increases the complexity and cost of the software development and to be noted that these are key quality determining factors.

It is needless to say that during the course of software development all models such as models to design, develop, deploy, and manage technology solutions have to be approved by IPR law authorities and CL authorities. Further, quality software product and technologies can be developed if software process engineering is based on Cyber space issues.

To achieve high quality software, requirements engineering (RE) consisting functional requirements, 'non-functional' or 'quality' requirements including cyber space issues have to be elicited from the customer and environment (cyber society) and to be represented in a requirements document in order to provide the software designer and tester a complete and correct specification. Conventional RE methods focuses mainly on functional requirements and to some extent non-functional requirements but Cyber space issues are usually not seen.

In general quality software could be improved by capturing functional requirements, non-functional requirements and applicable cyber space issues. Failing to capture and analyze any one of these issues during requirements engineering does not guarantee the quality. The software engineering is not just applying sound engineering principles that ensure to meet customer requirements but also should focus on legal and ethical issues. The work shows a general formalization (doing complete formalization is difficult and challenging and case specific). The future work includes in depth legal issues based NFR engineering and effective modeling using SoftModToones.

\section{ACKNOWLEDGMENTS}

ARUN KUMAR B.R, MCA, M.Phil (CS) M.Tech (CS\& E) has submitted his Ph.D (CS) thesis to the Dravidian university, Kuppam, A.P, India. The author has published 15 research papers in National/International Journals and 11 papers in the proceedings of National/International Conferences including IEEE international conferences, wishes to place on record his sincere thanks to all those who helped in bringing out this paper.

\section{REFERENCES}

[1] Dukrok Suh, Junseok Hwang and Donghyun Oh," Do Software Intellectual Property Rights Affect the Performance of Firms? Case Study of South Korea", PP 307-312, 978-0-7695-3372-8/08 , (C) 2008 IEEE, DOI 10.1109/ICSEA.2008.73

[2] Rolan Abdukalykov, Ishrar Hussain, Mohamad Kassab, Olga Ormandjieva," Quantifying the Impact of Different Non-Functional Requirements and Problem Domains on Software Effort Estimation", 2011 Ninth International Conference on Software Engineering Research, Management and Applications, 978-0-7695-4490-8/11 (C) 2011 IEEE, DOI 10.1109/SERA.2011.45, pp-158-166.

[3] Jyh-sheng Ke, Institute for Information Industry, Taiwan," SOFTWARE INDUSTRY IN TAIWAN"

[4] Anargyros Tsadimas, Mara Nikolaidou, Dimosthenis Anagnostopoulos," Handling non-functional requirements in Information System Architecture Design", 2009 Fourth International Conference on Software Engineering Advances, 978-0-7695-3777-1/09 @ 2009 IEEE, DOI 10.1109/ICSEA.2009.18

[5] Naavi," Essentials of Cyber Laws for IT Professionals", Presented at Sairam Engineering College on February 18, 2003 during the Seminar on Cryptography.

[6] Randall Davis, Pamela Samuelson,Mitchell Kapor, Jerome Reichman," A New View of Intellectual Property and Software" COMMUNICATIONS OF THE ACM March 1996/Vol. 39, No. 3 page. No. 21-31. 
[7] Dr. Mrs. Pratibha Rasal," CYBER LAWS - A WAY AHEAD", International Conference on Cyber Law and Information Technology by Indian Law Institute, New Delhi, 2001", International Conference on Cyber Law and Information Technology by Indian Law Institute, New Delhi, 2001.

[8] Manish Lunker," Cyber Laws: A Global Perspective", manishl@india.com.

[9] Ruth Malan and Dana Bredemeyer," Defining NonFunctional Requirements"2001 BREDEMEYER CONSULTING WHITE PAPER 8/3/01.

[10] Boehm, B. "Characteristics of Software Quality" North Holland Press, 1978.

[11] Boehm, Barry e In, Hoh. "Identifying Quality-Requirement Conflicts”. IEEE Software, March 1996, pp. 25-35

[12] Chung L., "Representing and Using Non-Functional Requirements: A Process Oriented Approach" Ph.D. Thesis, Dept. of Comp.. Science. University of Toronto, June 1993. Also tech. Rep. DKBS-TR-91-1.

[13] Chung, L., Nixon, B., Yu, E. and Mylopoulos,J. "NonFunctional Requirements in Software Engineering" Kluwer Academic Publishers 2000

[14] Luiz Marcio Cysneiros and Julio César Sampaio do Prado Leite," Using UML to Reflect Non-Functional Requirements".

[15] Pressman, Scott (2005), Software Engineering: A Practitioner's Approach (Sixth, International ed.), McGrawHill Education, p. 388
[16] Arun kumar B.R," "Need to Strengthen the Cyber Laws", National Conference on Cryptology, NWC-Aug 2005 held in J.N. National College of Engineering, Shimoga, Karnataka,India.

[17] Arun kumar B.R, "Intellectual Property Rights in India's Cyber Laws", National Conference on "Recent Trends in Electronics Communication Engineering and Information Technology", 30th - 31st August 2006, NACTECIT-2006 held at CMR Institute of Technology, Bangalore, Karnataka, India.

[18] Arun kumar B.R, "Intellectual Property Rights: Software Piracy, Protection, Patent and Global Economy", National Conference on Computer Networks security and cryptography , 18th - 19th Feb 2009, held at Vellore Institute of Technology, Tamil Nadu, India.

[19] Ernst \& Yang, "The benefits of software IPR protection in china", www.mondaq.com.

[20] Klaus Pohl, Gernot Starke, Peter Peters," Workshop Summary First International Workshop on Requirements Engineering: Foundation of Software Quality, The proceedings of the workshop.

[21] Computer Law: Drafting and Negotiating Forms and Agreements, by Richard Raysman and Peter Brown. Law Journal Press, 1999-2008. ISBN 978-1-58852-024-1. 